\title{
SONORIDADES EM MEIO DIGITAL
}

\author{
Tereza Virginia de Almeida* \\ Ellen Berezoshi**
}

\begin{abstract}
RESUMO: O artigo tem como objetivo apresentar algumas reflexões sobre o fato de que o meio digital permite aos indivíduos produzir, compartilhar e receber arquivos sonoros. $O$ fenômeno representa uma transformação significativa nas experiências sensoriais na vida cotidiana, quando comparado com a cultura de impressão. No meio digital, entre a palavra escrita em textos e hipertextos estão disponíveis arquivos auditivos e audiovisuais. Este artigo aborda os arquivos de áudio porque eles ativam um sentido distinto da visão: a audição. Qual é o impacto real da possibilidade de troca de sons entre os indivíduos que não compartilham as mesmas condições espaço-temporais? Esta é a pergunta que atravessa o artigo. No entanto, nosso objetivo não é respondê-la, mas levantar um conjunto de problematizações que possam auxiliar pesquisas futuras.
\end{abstract}

PALAVRAS-CHAVE: Meio digital. Literatura. Sonoridade.

\section{Introdução}

O meio digital tornou-se o lugar de novos modelos de produção de arte. Para além de todas as transformações geradas pela hipertextualidade nas relações entre escrita e leitura, o meio digital possibilita experiências que ultrapassam a cultura do impresso através da presença de objetos visuais e audiovisuais com os quais a palavra se mescla e se renova ou das quais simplesmente se ausenta.

As técnicas que o meio digital fornece aos seus visitantes permanentes têm permitido a múltipla exploração sensorial. Este artigo pretende se concentrar nas sonoridades que emergem do meio digital, em que o sujeito se encontra diante do estímulo de palavras vocalizadas que lhe chegam através dos ouvidos e não mais da leitura. Além disto, o meio digital oferece um universo infinito de sons, para além da palavra, passíveis de configurar experiências estéticas.

\footnotetext{
* Tereza Virginia de Almeida é Professora de Literatura Brasileira na Universidade Federal de Santa Catarina em Florianópolis, Santa Catarina. Imeio: tvirginia2012@yahoo.com.br

*** Ellen Berezoschi é mestranda do Curso de pós-graduação em Literatura da Universidade Federal de Santa Catarina em Florianópolis, Santa Catarina. Imeio:ellen. berezoschi@gmail.com
}

\section{(c) $\mathrm{BY}$-NC-ND}

Esta obra está licenciada com uma Licença Creative Commons. 
A possibilidade de ouvir poemas on line, por exemplo, resgata a literatura em sua forma originária, aquela que se dá através da voz, anterior à era do impresso. Entretanto, não se trata aqui das performances em que ouvinte e poeta compartilham as mesmas condições espaço-temporais. Estamos diante de arquivos que podem ser reproduzidos infinitamente, arquivos digitais cuja capacidade específica de transportar a voz já foi nosso interesse anterior de reflexão (ALMEIDA, 2013).

Será interessante lembrar que, embora se entenda a performance como algo que acontece em um único espaço com a presença simultânea de emissor e receptor, é no corpo e o que nele efetivamente ocorre que Paul Zumthor encontra a efetiva compreensão do literário que não se dissocia da noção de performance. Diz Zumthor: "o que na performance oral pura é realidade experimentada, é, na leitura, da ordem do desejo. Nos dois casos, constata-se uma implicação forte do corpo (...)". (ZUMTHOR, 2007, p. 35). Para o medievalista, o discurso poético se diferenciaria justamente pela atuação forte do corpo na relação com a linguagem.

Não é de todo impossível afirmar que o arquivo sonoro ocupa um lugar intermediário entre a escrita e a performance oral não mediatizada, pois embora emissor e receptor não compartilhem o mesmo espaço, o som será sempre algo que se diferencia da escrita por adentrar o corpo do ouvinte através dos ouvidos. Em outras palavras, é possível afirmar que o arquivo digital sonoro representa uma maior participação corpórea em relação aquela que se dá diante da página impressa. 0 arquivo digital sonoro traria desde já o excesso, aquilo que transcende o caráter informacional da linguagem e que é justamente o que a palavra literária busca em seu uso transgressor da língua.

Claro está que a possibilidade de gravação e reprodução de sons não é algo novo. O registro de sonoridades remonta ao século $\mathrm{XIX}$. Já no século $X X$, o gramofone passou a integrar os espaços domésticos e, aos poucos, diferentes aparatos foram criados que permitiram ao cidadão comum a gravação de sons. 
O que se torna o traço marcante da cultura digital, entretanto, é não só a simplificação extrema dos mecanismos que permitem fotografar, filmar e gravar, hoje disponíveis em qualquer dispositivo móvel, mas, principalmente, a possibilidade do imediato compartilhamento de conteúdo com um número infinito de receptores. $\mathrm{O}$ arquivo torna ilimitado o número de reproduções do objeto. Neste sentido, a voz, humana ou fabricada, o som de pássaro, o ruído de trânsito que se gravam aqui pode, em questões de segundos, ecoar em milhares de outros espaços. Trata-se, portanto, de uma possibilidade infinita de experiências sensoriais oferecidas pelo arquivo sonoro que permite adentrar o corpo sonoridades oriundas de um outro espaço e tempo. Basta que pensemos na comparação entre o que ocorre com o corpo e com o imaginário diante da leitura de um texto ficcional e diante de sua audição. Na leitura, há um processo entre ler, imaginar e arrebatar-se. Na escuta, o corpo é antes de tudo arrebatado de forma que é possível ser afetado pelo som antes de qualquer inteligibilidade.

Neste sentido, Jean-Luc Nancy apresenta uma reflexão fundamental acerca do ouvir e daquilo que o som traz em si para além de seu significado, o que traz de onipresença, aquilo que insiste em permanecer, em atravessar os sujeitos, o que é tempo e espaço simultaneamente e que muda a configuração do tempo e ocupa espaço em todos os arredores. "Escutar" diz Nancy, "é estar ao mesmo tempo dentro e fora, estar aberto por fora e por dentro, de si para o outro e de si no outro" (NANCY, 2007, p. 14) ${ }^{1}$.

Desta forma, ao abordar as questões da percepção de mundo e das relações estéticas e sensoriais que a cultura digital pode oferecer, este artigo pretende não só descrever experiências sensoriais e literárias em meio digital, como também levantar reflexões acerca do ouvir e do falar. É de fundamental relevância compreender questões relativas ao corpo e aos sentidos que fogem da experiência da leitura das palavras. O ritmo, o som, o canto, tudo isso que retorna como um novo modo do fazer poético, como novas experiências poéticas que conseguem resgatar a ressonância da fala, da voz, da música, dos ruídos e de tudo o que chega aos

\footnotetext{
${ }^{1}$ Todos os textos em língua inglesa são citados no presente artigo em tradução nossa. 
ouvidos.

A sonoridade poética que, desde a invenção da imprensa, passou a ser mediada pela página impressa está hoje próxima de nós. Através de recursos simples como o youtube, a poesia pode ser compartilhada. Podem-se ouvir as sinfonias de Beethoven, dormir aos sons de Nature Sounds ${ }^{2}$, ou mesmo conhecer antigos poemas musicados ou declamados, entrar em contato com a poesia das ruas ouvindo rap (rythm and poetry), ouvir as mais diversas canções. Além disto, todos os sujeitos são potenciais agentes de outras experimentações ainda não realizadas, pois qualquer pessoa que acessa a internet pode elaborar tais produções sonoras com mínimos recursos e disponibilizar na rede.

Quais os limites do corpo nessa era digital e, principalmente, em relação ao ouvir e ao falar (a voz)? Os sujeitos são atravessados pelos sons, não há como não ouvir, mesmo que seja a voz que está dentro de cada um dos sujeitos, as vozes mecânicas do computador etc. Não há como escapar dos sons que interpelam nossos ouvidos e que produzem, além de sentido, poesia. Não há como escapar da singularidade da voz e do que se perde (ou não) desta singularidade quando somos confrontados com um novo mundo de inteligência artificial, de computadores que também produzem vozes. O desafio que aqui se coloca diz respeito a indagar acerca do lugar da estética sonora no meio digital, em um momento em que todas as percepções de tempo e espaço são reconfiguradas.

\section{O som ambiente e os meios digitais}

Os limites do cotidiano na sociedade capitalista e mecanicista, além de aproximar os sujeitos das máquinas, afastou da vida a natureza. Os recursos digitais possibilitaram uma reaproximação, mesmo que de maneira artificial, através das

2 Nature Sounds é uma coleção de vídeos disponíveis no Youtube, nos quais as imagens não são o central, pois são apenas fotos. O foco são os sons da natureza. Alguns vídeos chegam a ter dezesseis horas seguidas de sons de água, pássaros, vento etc. Muitas pessoas utilizam como técnica de relaxamento ou como som ambiente para dormir. Além disso, é possível também encontrar os City Sounds, que possuem a mesma proposta, porém com sons de cidade: carros, ônibus passando etc. Exemplo através do link: http://www.youtube.com/watch?v=b2njHW9ydWs

Texto Digital, Florianópolis, Santa Catarina, Brasil, v. 11, n. 1, p. 355-368, jan./jun. 2015. ISSNe: 1807-9288. 
máquinas. A chance de ouvir por oito horas seguidas o Nature Sounds através do Youtube, faz com que, a qualquer momento do dia, pelo computador ou pelos dispositivos móveis, os sujeitos possam transportar-se para o meio de uma floresta, para uma cachoeira, para uma tempestade de raios, para perto dos animais e assim por diante, tudo isso, apenas pelo ouvido. O som, mesmo que gerado pela máquina, apura os sentidos e as sensações e, as imagens que passam aos nossos olhos na vida real e simbólica, ganham o som da natureza, mesmo que seja dentro de nossa própria casa, no meio de uma capital movimentada.

O sonoro ecoa, ressoa, abre um campo de percepção rítmica que configura os sujeitos, seus corpos, seus movimentos, o timbre da voz e a percepção do mundo. Ao ouvir Nature Sounds, nosso espaço e nosso tempo são afetados por aquilo que ressoa da natureza. Se ouvir permite imaginar o pássaro que canta, o vento que passa, a folha que mexe e a água que corre, a experiência da escuta ainda assim está além da significação. Tentar apenas, pois não há como atribuir significados plenos aos sentidos físicos. O signo não transparece o corpo, não traduz o que toca os nossos ouvidos. O som é presença e se presentifica como experiência corpórea ao se oferecer como ressonância, esta que seria para Nancy como uma fundação, uma primeira e última profundidade do "sentido". (NANCY, 2007, p. 6).

Nestas reflexões é possível pensar que a vida e a rotina, conforme caminham apressadamente, permanecem trazendo sons do cotidiano: o trânsito, as vozes, os helicópteros, as sirenes, a cidade que é quase uma orquestra, sons que se misturam com odores, com imagens, sons nas casas, dos meios eletrônicos, do trabalho, das máquinas e tudo isso de certa maneira, produz efeitos e sentidos e não necessariamente significados. Mas há realmente como manter-se no silêncio absoluto por algum momento? Thomas Trummer sugere algumas reflexões neste sentido ao narrar algumas experiências em torno da voz e uma delas é em torno de John Cage, artista estadunidense, que publica um texto chamado "Lecture on nothing", que se inicia com a afirmação: "Estou aqui", seguida de um intervalo a que se seguira a segunda frase "e não tenho anda a dizer": 
Era preocupação de John Cage provar que não havia ausência. O som está sempre lá antes de sua concepção. Isto se manifesta na impossibilidade do fade-out. Em escuta, não há nem pausa nem interrupção porque, ao contrário de nossos olhos, não podemos fechar os nossos ouvidos. Cage estava interessado na quietude; ele nela via uma atmosfera, um nada que desaparece e se desintegra em algo assim que a escuta nela se foca. (TRUMMER , 2007, p . 8).

Para Cage, não há um espaço vazio de som, mesmo quando somos confrontados com o que definimos como silêncio, há sempre os sons de nossos corpos, de nossa respiração, ou mesmo, a voz interior, que nunca desaparece de nós. Este confronto, com nosso corpo e os sons que pode produzir, é um confronto de inquietude: "complete silence makes us unsure; it leads us back to ourselves" (TRUMMER, p. 13). O silêncio absoluto só se torna possível no caso da surdez física ou, ainda, da morte.

Além do Nature Sounds, que pode aproximar os sujeitos da natureza perdida, é possível encontrar também on-line o link City Sounds ${ }^{3}$, que reproduz sons da cidade, em geral, carros, vozes, sirenes, buzinas, bicicletas e tudo o que estamos habituados a presenciar a todos os momentos. Esses links estão associados a técnicas de relaxamento, muitas vezes encontrados como barulhos com os quais os sujeitos possam adormecer em sons ambientes. De alguma forma, muitas pessoas aderem a essas tecnologias para que não durmam em "completo silêncio" em seus quartos. O silêncio pode ser inquietante, pois traz os sujeitos para eles mesmos e para alguns só é possível acomodar-se e tranqüilizar-se através dos sons.

É interessante ainda ler os comentários nos vídeos que são postados. Grande parte dos sujeitos que ouvem Nature Sounds ou City Sounds dizem que os vídeos os ajudam a dormir, a estudar, dizem que é bom para seus filhos dormirem. De alguma maneira as pessoas sentem uma necessidade extrema de sons e de barulho para poderem relaxar. Os que estudam ouvindo a estes sons, dizem que preferem desta forma para não se distraírem com os sons e vozes dos lugares onde realmente se encontram. Os sujeitos podem ser transportados para o meio de uma floresta ou

3 Disponível no Youtube, através de vários links, como por exemplo: https://www.youtube.com/watch?v=eXHURall7hA

Texto Digital, Florianópolis, Santa Catarina, Brasil, v. 11, n. 1, p. 355-368, jan./jun. 2015. ISSNe: 1807-9288. 
para o meio de uma metrópole apenas através do Youtube como forma de não conviverem com aquilo para qual o suposto "silêncio" os transporta, para si mesmos. Mas é impossível fugir dos sons, não há vácuos nem vazios.

O som se encontra em todos os lugares. E na verdade ele não se encontra, pois sua presença é constante, ele não se encontra porque ele é som o tempo inteiro, ele não se perde. O som penetra nos sujeitos de tal forma que não há tempo nem espaço para som; o som é som em qualquer tempo e em qualquer espaço, numa forma materializada de onipresença, transcendendo as barreiras de espaço e tempo. $O$ som apenas não pode se propagar no vácuo. Apenas no vazio absoluto o som não pode entrar em ressonância, não pode reverberar. Poderíamos dizer então que onde há espaço, há necessariamente som? Talvez, mas para além das leis da física, o que se quer analisar aqui é a oportunidade de se escolher aquilo que se quer ouvir, através da máquina.

O som da máquina, mesmo que mecânico, possibilita aos nossos ouvidos a chance de poder escolher aquilo que queremos ouvir, os sons da natureza, uma canção, a declamação de um poema, tudo através de fones de ouvido e aparelhos eletrônicos. Nossas percepções são reconfiguradas, principalmente pela transformação no espaço-tempo que sofremos com toda a vinda de novas mídias de tecnologias.

\section{A voz e o meio digital}

Thomas Trummer assinala que hoje a voz é mais ouvida mediada por máquinas do que em seu estado original. "No telefone, no rádio, na televisão ou na reprodução digital não ouvimos a voz natural, mas o eco de sua conversão tecnológica" (TRUMMER, 2007, p. 22). Além disto, a voz mediatizada que se ouve no meio digital não coincide com seu contexto de produção: é uma voz esquizofônica (VALENTE, 1999, p.119-152). O que significa que a voz do arquivo digital se oferece como um objeto que deve ser convincente sem se produzir através da consciência em torno do perfil de seus receptores, tal como na comunicação que se dá na presença do ouvinte. O distanciamento entre o falante e o ouvinte é característico 
das tecnologias de gravação, e é conhecido, por exemplo, do trabalho de um cantor ao gravar seu disco, já que ele desconhece sua audiência. Entretanto, na cultura digital, é o cidadão comum que pode falar, fazer ecoar sua voz para uma audiência anônima instantaneamente, assim como pode gravar e disponibilizar qualquer sonoridade de seu contexto.

Sabendo-se que aquilo que se escuta transcende as condições espaço-temporais, percebe-se que a voz também não é apenas o que se escuta para se entender uma mensagem, a voz produz algo além de seus fonemas que significam algo. Inclusive, os fonemas são apenas representações gráficas dos sons, não captam os sons em sua forma sensorial, os fonemas não dão conta de expressar tudo aquilo que a voz carrega em si. A voz carrega um algo a mais, algo de poético que transcende significantes e significados, mas demonstra algo de interior dos sujeitos, algo que quer se fazer entender, um significado para além das palavras e das mensagens da comunicação tradicional, algo de singularidade, de identidade, algo que produz e acarreta em uma profundidade rítmica para além da fala. Observemos como Mladen Dolar aborda essas questões:

\footnotetext{
O que singulariza a voz no vasto oceano de sons e ruídos, o que define a voz como especial entre a matriz infinita de fenômenos acústicos é a sua relação interna com o significado. A voz é algo que aponta para o significado, há algo nela como uma flecha que levanta a expectativa de significado, a voz é uma abertura na direção do significado. Sem dúvida, pode-se atribuir significado para todos os tipos de sons, mas eles parecem ser dele privados "em si mesmos", enquanto a voz tem uma ligação íntima com o significado, é um som que parece dotado em si da vontade de " dizer algo ", com uma intencionalidade interior. (DOLAR, 2007, p. 31)
}

Esse significado intrínseco à voz é algo totalmente diferente dos signos que constituem o mundo a partir da linguagem. A voz tem essa intencionalidade de produzir significado, da qual Dolar fala, e a produz a partir de sensações e sentimentos de cada sujeito. Isso é totalmente perceptível na música. A canção quando cantada, para além de suas palavras, reverbera um outro significado. As múltiplas interpretações de uma canção e as variadas vozes que a interpretam modificam completa e substancialmente sua significação. Ainda no Youtube, podemse acessar vários exemplos dessas canções em que a voz transcende as palavras, 
como várias versões diferentes das mesmas músicas, cantadas por pessoas famosas, por pessoas comuns, versões modificadas por meios eletrônicos etc.

A voz é carregada por um corpo e por isso sua capacidade de produzir um significado que ultrapassa as barreiras da linguagem. É possível perceber isso no $R A P$, por exemplo, em que cada performance é diferente da outra, cada corpo é um corpo diferente e o mesmo sujeito pode criar múltiplas versões da mesma canção. O corpo é sempre um corpo diferente a cada momento e a voz, por consequência, não será a mesma. Podemos perceber isso, por exemplo, quando vemos duas performances diferentes da mesma música. Quando vemos a performance da canção "Negro Drama" dos Racionais MC's no show que originou o DVD "1000 trutas 1000 tretas" $^{4}$ do ano de 2006 e quando vemos a mesma canção ser apresentada em outro espaço, em outro tempo, como na Virada Cultural de São Paulo no ano de $2013^{5}$, é possível ver que há outras vozes, outra intencionalidade, outro público, outra performance. O primeiro vídeo, sete anos antes do segundo, é a produção de um DVD, na Zona Leste de São Paulo em que o público, em sua grande maioria negro, não só canta junto, como exige uma performance de grande engajamento, já que o que se canta diz muito de sua história. O segundo vídeo, filmado na Virada Cultural de São Paulo, possui um público mais heterogêneo, que, não necessariamente, clama pela mesma performance. O mais importante de tudo isso é perceber que não só os anos modificam as vozes dos mesmos sujeitos, como também a interação sociocultural, o meio em que estão inseridos. Cada situação pede vozes diferentes que vão produzir distintas experiências sensoriais.

Se a voz traz em si o destino à significação, traz também aquilo que a transcende e onde residiria segundo Mladen Dolar, o uso poético da língua:

Aquilo que não contribui para o significado é então utilizado como material para efeitos poéticos, funciona como a fonte para repetições, ritmos, rimas, ecos sonoros, padrões métricos, toda a panóplia complexa que produz o encanto da poesia. A voz é a fonte de um efeito estético que se apresenta distinto da função referencial ou informativa da língua, é o seu efeito

$4 \quad$ Disponível no link: https://www.youtube.com/watch?v=CHLUJ-o8OsU

5 Disponível no link: https://www.youtube.com/watch?v=c3gzQdO_dEY

Texto Digital, Florianópolis, Santa Catarina, Brasil, v. 11, n. 1, p. 355-368, jan./jun. 2015. ISSNe: 1807-9288. 
colateral que pode ser visto na sua maior simplicidade nas rimas infantis e na poesia nonsense, como a que foi ampla e brilhantemente praticada por Lewis Carroll e Edward Lear e que se desenvolve em meros sons sem sentido. (DOLAR, 2006, p. 33)

As declamações de poemas na internet tornaram possível novas experiências com a voz e isso que Dolar traz, sobre a estética da voz como material para a poesia, como efeitos poéticos fica hoje muito mais próximo dos sujeitos do que antes, na era do livro escrito. O poema escrito limitou a compreensão da poesia, além disso, não só sua compreensão, mas a beleza que é não precisar compreendê-la, enquanto significação, mas sim abrir os sentidos para seus sentidos múltiplos. Na internet é fácil encontrar vários exemplos disso: versões de "Jabberwocky" de Lewis Carroll, versões das antigas animações de Dr. Seuss ${ }^{7}$, ou mesmo poemas brasileiros, brilhantemente declamados por seus autores ou por outras pessoas.

Podemos explorar o mundo virtual e encontrar autores como Vinicius de Moraes declamando seus próprios poemas (antes era possível somente na compra do álbum), ou podemos encontrar infinitas versões de várias pessoas declamando seus mesmos poemas. Uma infinidade de vozes pronunciando as mesmas palavras, dando ritmos aos poemas e dando diferentes versões, em diferentes vozes. A experiência é extremamente rica e próxima de nós. Além disso, cada um de nós pode hoje gravar nossas versões dos mesmos poemas e compartilhá-las com todo o mundo. A voz é o que torna a poesia algo material, algo que pode ser de fato experienciado, vivido, e principalmente, sentido. Somente a voz pode dar contorno à poesia, naquilo mesmo e $\mathrm{m}$ que transcende a significação. Mladen Dolar assim define a voz como o elemento que embora aponte na direção do sentido é a ele recalcitrante: a voz seria "o elemento não linguístico, extralinguístico que possibilita o fenômeno da fala, mas que não pode ser discernido pela linguística (DOLAR, 2006, p. 15).

A contribuição de Dolar traz uma reflexão importante para a era digital: como viver em mundo no qual a máquina também produz voz? Como é a experiência de não

6 Disponível no link: https://www.youtube.com/watch?v=ZpKcqraRdfs

7 Disponível no link: https://www.youtube.com/watch?v=I5fyOmk-5qg

Texto Digital, Florianópolis, Santa Catarina, Brasil, v. 11, n. 1, p. 355-368, jan./jun. 2015. ISSNe: 1807-9288. 
saber qual é o corpo que produz a voz que fala? São reflexões que ainda não possuem respostas, mas vale a pena conhecer suas imbricações e seus aprofundamentos.

A voz precisa de um corpo para materializar-se. É o corpo que une o significante, as palavras à voz. Não conhecer este corpo é como estar em contato com uma voz onipotente, a voz de um deus, de algo que não vemos, não conhecemos e não podemos processar. Um filme que abarca a reflexão sobre a voz gerada pela máquina é o filme "Her", lançado em 2013 e dirigido por Spike Jonze. Neste filme, um homem interage com uma máquina que possui voz e personalidade femininas e aos poucos a máquina passa a ser sujeito para este homem. A partir deste filme, podemos levantar ainda outros questionamentos: é possível interagir com uma máquina sem atribuí-la características humanas? Somos capazes de construir relações com máquinas ou através delas sem sentirmos falta de um corpo, daquilo que torna a voz humana (o corpo)?

A propósito de experimentações, é possível baixar programas que alteram nossas próprias vozes. Muitos cantores hoje recebem a contribuição das máquinas para modificarem suas vozes; os discos que compramos, ou as músicas que ouvimos online, em sua grande maioria, possuem alterações eletrônicas e digitais e não se sabe até que ponto isso pode ou não interferir na singularidade das vozes que ouvimos. No texto Voice and Void de Thomas Trummer, pode-se ver que questões deste tipo já foram levantadas há muito por Walter Benjamin, por exemplo, que já se referia ao processamento tecnológico da voz como a perda do compartilhamento espacial entre falante e ouvinte. Ainda em Trummer vemos que:

\footnotetext{
A voz pertence ao quadro geral da aparência corporal; seu som pode ser magnético, e pode igualmente surgir como repelente e irritante. A voz transmite estados de ânimo para nós como nervosismo, preocupação, alegria ou confiança e, por último mas não menos importante, transmite as características da pessoa que fala , tais como identidade ou uma afiliação à idade ou sexo. (TRUMMER, 2007, p. 12)
}

8 Pode-se conferir o trailer oficial do filme "HER" através do link: https://www.youtube.com/watch?v=gvlj2nGczol 
Mas se Trummer está a se referir à voz natural, é possível questionar aqui o que se coloca de rastro desta voz quando processada. É possível ainda perguntar se uma voz artificialmente fabricada não será ainda uma voz que tem como referência a voz humana sendo tão potente ou mais em sua capacidade de produzir experiências sensoriais singulares.

Norie Neumark procura confrontar qualquer tentativa de abordar a voz no contexto contemporâneo a partir da noção de autenticidade. Para tanto, Neumark assinala o caráter performativo da linguagem de uma maneira geral e como a cultura digital, ou em rede, potencializa as performatividades em torno de si. Se atentamos para este alerta da pesquisadora se torna possível entender que a diferença entre a voz natural e a voz artificial reside nas diferentes performatividades e não na maior autenticidade da primeira. Para Neumark, a voz deve ser compreendida enquanto ação e não como representação: "A voz cria e tensiona a "identidade" ao invés de simplesmente transmiti-la ou expressá-la” (NEUMARK, 2007, p. 96).

Assim, seria importante perceber que a voz, o timbre que configuramos a partir da tecnologia são formas de construção de identidades tanto quanto as próprias vozes consideradas "naturais". Pois, assim como os corpos que efetivamente portamos, as vozes também serão resultado dos usos para a ação que fazemos dos recursos biológicos e nunca a atuação desses recursos sem mediações. Em outras palavras, assim como a cultura em que estamos inseridos atua sobre nossos corpos também modela a voz que falamos. O aparato tecnológico seria assim apenas mais uma forma de mediação. E se uma voz totalmente artificial como a de Her não é em si expressão de uma subjetividade, o é em relação a seus criadores. Além disto, o personagem no filme se envolve coma voz justamente porque esta tem atributos que os remetem a experiências anteriores com corpos femininos.

Adriana Cavarero dedicou um importante estudo que demonstra que a trajetória da filosofia ocidental se deu a partir do que ela denomina de "desvocalização do logos", com a prevalência do visual sobre o vocal e auditivo. "A metafísica sonha desde 
sempre", diz Cavarero, "com uma ordem videocêntrica de significados puros: o significante verbal é, para ela, um estorvo, agravado pelo fato de se radicar obstinadamente na esfera acústica" (CAVARERO, 2011, p. 58).

A inevitável permanência da voz nas interações cotidianas, entretanto, correu em paralelo a toda ambição do pensamento filosófico em fazer da racionalidade silêncio. E sua presença ostensiva no meio digital, em que ela pode imprimir-se no arquivo e perpetuar-se tanto quanto a palavra impressa, convida a que se revisitem os lugares do corpo em suas relações com a voz e com a escrita no contexto contemporâneo em que todos os sentidos são convocados em nome de um saber corpóreo que desafia a prevalência da racionalidade como forma de conhecimento, que caracterizou a modernidade, sempre desfiada, porém pelo próprio fazer artístico. Pois na literatura, sabemos, ali mesmo onde a reconhecemos como tal a sonoridade da palavra jamais se fez em segundo plano.

\section{Considerações finais}

Problematizar questões tão contemporâneas como a literatura em meio digital não é uma fácil tarefa. As questões são várias e múltiplas e, em sua grande maioria, não há respostas. O meio digital possibilitou diferentes percepções de mundo e dos sujeitos, diferentes apreensões da realidade e, além disso, a multiplicidade de realidades em um mesmo universo. Para não cair em um relativismo completo ou em uma efemeridade absoluta existem coisas que ainda nos prendem ao mundo real, os nossos corpos. Porém, percebemos que até mesmo nossos corpos podem ser modificados e transformados pelas máquinas. Afinal, tudo aquilo que tocamos, em certa medida, também nos toca.

Para finalizar, é importante deixar em aberto o que pode vir a ser da poesia e da literatura, num contexto em que ela passa a se imprimir fora da página impressa. Trata-se sim de repensar todo um sistema, o literário, suas crenças e dogmas, sua institucionalização, a partir do momento em que a poesia parasse estar de novo solta por aí na infinita rede de computadores e suas interconexões. 


\section{SOUNDS IN DIGITAL MEDIA}

ABSTRACT: The article aims to present some reflections on the fact that the digital media enables individuals to produce, share and receive sound files. The phenomenon represents a significant transformation in sensorial experiences in everyday life when compared to print culture. In digital media, between the written word in texts and hypertexts there available are available audio and audiovisual archives. This article addresses the audio archives because they activate a sense distinct from the vision: listening. What is the actual impact of the possibility of exchange of sounds between individuals who do not share the same special and time conditions? This is the question that runs through the article. However, our goal is not to answer it but to raise a set of problematizations that can assist future research.

KEYWORDS: Digital media. Literatura. Sonority.

\section{Referências}

ALMEIDA, Tereza Virginia de. A voz no arquivo digital. Texto digital, vol. 9, n. 2, Florianópolis, 2011, p. 20-34.

CAVARERO, Adriana. Vozes plurais. Tradução de Flavio Terrigno Barbeitas. Belo Horizonte: UFMG, 2011.

DOLAR, Mladen. A voice and nothing more. Cambridge, MIT Press, 2006.

DOLAR, Mladen. Six lessons on voice and meaning In: In: TRUMMER, Thomas. Voice\&Void. Connecticut: The Aldrich Contemporary Art Museum, 2007

NANCY, Jean-Luc. Listening. Tradução de Charlotte Mandell. New York: Fordham University Press, 2007.

NEUMARK, Norie. Doing things with voices. In: NEUMARK, Norie. Vocal aethetics in digital art and media. Cambridge: the MIT Press, 2010. s

ZUMTHOR, Paul. Performance, recepção e leitura. Tradução de Jerusa Pires Ferreira e Suely Fenerich. 2a edição, São Paulo: Cosac Naify, 2007.

Texto recebido em: 19/05/2015.

Texto aceito em: 24/07/2015. 